\title{
Effects of weathering on mechanical and morphological properties cork filled green polyethylene eco-composites
}

\author{
Gabriela Celso Melo Soares de Vasconcelos ${ }^{1}$, Laura Hecker de Carvalho ${ }^{2}$, Renata Barbosa ${ }^{3}$, \\ Rita de Cássia de Lima Idalino ${ }^{4}$ and Tatianny Soares Alves ${ }^{3 *}$ (i)
}

\author{
'Programa de Pós-graduação em Ciência e Engenharia de Materiais, \\ Universidade Federal do Piauí - UFPI, Teresina, PI, Brasil \\ ${ }^{2}$ Programa de Pós-graduação em Ciência e Engenharia de Materiais, Universidade Federal de Campina \\ Grande - UFCG, Campina Grande, PB, Brasil \\ ${ }^{3}$ Curso de Engenharia de Materiais, Programa de Pós-graduação em Ciência e Engenharia de Materiais, \\ Universidade Federal do Piauí - UFPI, Teresina, PI, Brasil \\ ${ }^{4}$ Curso de Estatística, Universidade Federal do Piauí - UFPI, Teresina, PI, Brasil \\ *tsaeng3@yahoo.com.br
}

\begin{abstract}
This study aims to evaluate the effects of natural weathering in the city of Teresina, State of Piauí, Brazil, on the morphology and mechanical properties of eco-composites based on high-density green polyethylene, powdered cork and compatibilizer processed in a twin-screw extruder and injection molded. The analyses revealed that although weathering induced surface bleaching of eco-composites and cracking, these effects were not intense in the compatibilized samples. The tensile properties of the investigated materials were affected by abiotic degradation, which led to a reduction of the tensile strength and elastic deformation of the eco-composites, however, the incorporation of PEgMA was fundamental for the maintenance of mechanical performance after natural aging. In general, the results obtained were satisfactory for external applications of the compatibilized eco-composite with $15 \%$ cork in the proposed weathering range, which indicates its possible use in temporary constructions.
\end{abstract}

Keywords: composites, compatibilizer, extrusion, colorimetry, natural aging.

How to cite: Vasconcelos, G. C. M. S., Carvalho, L. H., Barbosa, R., Idalino, R. C. L., \& Alves, T. S. (2020). Effects of weathering on mechanical and morphological properties cork filled green polyethylene eco-composites. Polimeros: Ciência e Tecnologia, 30(1), e2020011. https://doi.org/10.1590/0104-1428.04919

\section{Introduction}

The construction industry is the second-largest consumer of plastics in the world ${ }^{[1]}$, as it exploits and takes into account the lightness and durability of these materials ${ }^{[2]}$. Plastics, however, decompose fairly slowly and end up harming the environment after use. An alternative to polymer applications in the construction industry in a sustainable way is through the production of composites reinforced by plant material, as they are advantageous in terms of weight, cost, strength, recyclability, and ease of maintenance ${ }^{[3,4]}$.

However, many of these applications are intended for external use and the stability of the polymeric composites, when exposed to weathering, is reduced. The combined effects ultraviolet solar radiation, moisture, and temperature oscillation can lead to matrix photodegradation and embrittlement as well as the fast degradation of vegetable fiber components (cellulose, hemicellulose, lignin, and extractives). These combined effects are also deleterious to fiber/matrix adhesion and, consequently, to effective filler/matrix load transfer, thus reducing composite mechanical properties as well as changing product appearance ${ }^{[5-7]}$. Contributing factors for this reduction include changes in matrix crystallinity, composite surface oxidation and interfacial degradation ${ }^{[8-10]}$.

Mechanical properties stand out among the properties most studied in polymer composites subjected to ultraviolet, natural or accelerated weathering as these conditions not only directly affect material suitability for a given application but can significantly alter the physical properties and aesthetics of the product. Matuana, Jin \& $\operatorname{Stark}^{[7]}$ studied the influence of accelerated ultraviolet radiation exposure on high-density polyethylene (HDPE) composites reinforced with wood flour, coextruded or not with a clear HDPE cap layer, and their results showed discoloration, loss of wood components and increase of surface roughness after exposure. Bajwa, Bajwa \& Holt ${ }^{[3]}$ evaluated the performance of eco-composites consisting of HDPE, three types of biofibers (oak, cotton, and guayule), two coupling agents (NE 556-004 and TPW 243) and one lubricant (TPW 113), after accelerated aging. They observed that aging led to porous surfaces, color changes and surfaces rich in exposed biofibers, as well as a reduction in mechanical properties of the composites. Their data also indicated that the coupling agent was responsible for 
maintaining the mechanical properties of the composites after exposure. Badji et al. ${ }^{[11]}$ investigated changes in the visual appearance, surface topography and mechanical properties of polypropylene/wood composites exposed to natural and artificial UV radiation. Aging caused surface bleaching, exposure of wood particles and numerous microcracks. After exposure, matrix behavior evolved from ductile to brittle with greater intensity in natural weathering. The elongation of the eco-composites after natural weathering, when compared to the matrix, was higher due to a stabilizing role of the lignin contained in wood flour. The stiffness and strength are not impacted by artificial aging in contrast to natural aging but the elongation values are lower for artificial weathering than for natural. These authors suggest that artificial weathering conditions cause much less degradation of mechanical properties than natural weathering.

An alternative material to use in polymer composites is cork, an industry by-product used in small quantities and in low value-added applications ${ }^{[12-14]}$, such as feed the boilers in industrial processes ${ }^{[14,15]}$. The material has a similar appearance to wood and can be applied in composites with thermal, acoustic and vibration insulation functions (walls, ceilings, and floors), false ceilings, cladding, baseboards, mortars, insulating joints, and expansion or compression joints, among others ${ }^{[14,16]}$. The raw material is relevant for incorporation in composites ${ }^{[17]}$ due to its low density, low permeability to liquids and gases, good compressibility and elasticity, low coefficient of thermal conductivity, wear resistance, mechanical characteristics, corrosion and fire resistance $\mathrm{e}^{[15,17,18]}$.

The sustainable character of the composite can be increased with the use of high-density green polyethylene, a polymer produced from ethylene monomer obtained by the dehydration of ethanol from sugarcane. Its composition is exactly the same as that of synthetic, non-renewable polyethylene, and has the same performance and characteristics ${ }^{[19]}$.

The major challenge in the production of polymer-cork composites is to promote good interfacial bonding between the components ${ }^{[16]}$. Since cork is a polar material and most polymer matrices are nonpolar, compatibility with these materials is low. As a result, load transfer from the matrix to the reinforcing agent, which takes place at the interface, is hindered and so are the product's mechanical properties ${ }^{[20,21]}$. The addition of functionalized polymers, such as those containing maleic anhydride groups in their composition, is considered to be an effective strategy to improve interfacial adhesion in these systems ${ }^{[4,13,16]}$.

Thus, the aim of this work is to evaluate the morphology and mechanical performance of high-density green polyethylene/cork eco-composites with and without the addition of a polar compatibilizer based on maleic anhydride, before and after exposure to abiotic degradation. This is an eco-friendly and sustainable product being intended for application in civil construction.

\section{Materials and Methods}

\subsection{Materials}

High-density green polyethylene, hereinafter referred to as GPE, supplied by Braskem, grade SHA7260, density $0.955 \mathrm{~g} . \mathrm{cm}^{-3}$ and flow rate $20 \mathrm{~g} / 10 \mathrm{~min}^{-1}$ (temperature $190^{\circ} \mathrm{C}$ and $2.16 \mathrm{~kg}$ mass) was used as the matrix. Powdered cork (PC) (\#74 $\mu \mathrm{m})$, used as reinforcement, was supplied by Corticeira Paulista / SP, density 65 an 85 g/l, humidity 7\%, and particle size distribution as per Table 1. Maleic anhydride grafted high-density polyethylene, labeled PEgMA, commercial-grade Orevac ${ }^{\circledR} 18507$, density 0.954 g.cm ${ }^{-3}$ and flow rate $5 \mathrm{~g} .10 \mathrm{~min}^{-1}$ (temperature $190{ }^{\circ} \mathrm{C}$ and $2.16 \mathrm{~kg}$ ), purchased from Arkema Innovative Chemistry was used as a coupling agent.

\subsection{Composites preparation}

The $\mathrm{PC}$ was previously dried at $80^{\circ} \mathrm{C}$ for 24 hours in an air-circulating oven and then tumble mixed with high-density GPE and polar compatibilizer (PEgMA) in the proportions indicated in Table 2. The compositions were processed in a modular twin-screw co-rotating extruder, NZ brand, $\mathrm{SJ}-20$ model, with a diameter of $22 \mathrm{~mm}, \mathrm{~L} / \mathrm{D}=38$ and a shape factor of 1.48 . The screw used is composed of two sections of intensive mixing formed by mixing blocks. The feed rate was $5 \mathrm{~kg} / \mathrm{h}$ and the temperatures in the heating zones of the extruder Z1, Z2, Z3, Z4, Z5, and Z6 and the matrix were, respectively: $160,170,170,180,180,180$ and $230^{\circ} \mathrm{C}$, and the screw speed was $250 \mathrm{rpm}$.

After extrusion, the composites were ground and dried in an oven at $80^{\circ} \mathrm{C}$ for 24 hours. Tensile test samples (ASTM D 638 standard) were injection molded in a FLUIDMEC injection molding equipment operating with pressure $55 \%$, a temperature profile of 210 and $200{ }^{\circ} \mathrm{C}$ at heating zones $\mathrm{Z} 1$ and $\mathrm{Z} 2$, injection time of $4 \mathrm{~s}$, the cooling time of $35 \mathrm{~s}$ and die temperature $41,8^{\circ} \mathrm{C}$.

\subsection{Abiotic degradation}

The samples were exposed to natural weathering in the city of Teresina-Piauí, at the Federal University of Piauí (UFPI) campus, in 2017, during 13 weeks (2184 h), from September $4^{\text {th }}$ to December $3^{\text {rd }}$, following ASTM D5272-08, ASTM D1435-12, and G7/G7M-13 standards. The experiment was carried out in the driest season where the highest values of temperature and ultraviolet index are regionaly expected. Morphological and mechanical tests were performed after 45 (10/18/2017) and 90 (12/03/2017) days of exposure and the results were compared to the

Table 1. Cork particle size distribution.

\begin{tabular}{cc}
\hline Characteristics & Specification \\
\hline Mesh $50-(0.30 \mathrm{~mm})(\%)$ & 20 to 50 \\
Mesh $60-(0.25 \mathrm{~mm})(\%)$ & 10 to 45 \\
Mesh $80-(0.18 \mathrm{~mm})(\%)$ & 5 to 30 \\
\hline
\end{tabular}

Table 2. Sample compositions.

\begin{tabular}{cccc}
\hline Sample & $\begin{array}{c}\text { GPE } \\
\text { (\% by weight) }\end{array}$ & $\begin{array}{c}\text { PC } \\
\text { (\% by weight) }\end{array}$ & $\begin{array}{c}\text { PEgMA } \\
\text { (\% by weight) }\end{array}$ \\
\hline GPE & 100 & - & - \\
GPE/5PC & 95 & 5 & - \\
GPE/10PC & 90 & 10 & - \\
GPE/15PC & 85 & 15 & - \\
GPE/5PC & 90 & 5 & 5 \\
/5PEgMA & & & 5 \\
GPE/10PC/5PEgMA & 85 & 10 & 5 \\
GPE/15PC/5PEgMA & 80 & 15 & 5 \\
\hline
\end{tabular}


non-weathered samples. Climatic conditions data were collected at the National Institute of Meteorology (Inmet) meteorological station A312, located in Teresina/PI.

\subsubsection{Climatic conditions during abiotic degradation}

Climate data collected during the experimental period showed high temperatures and high ultraviolet index (UVI) (Table 3), factors responsible to intensify the speed of the photooxidative reactions which cause degradation and, hence, reduce the durability of the polymer products ${ }^{[22-24]}$.

Mean temparature ranged between 21.9 to $38.2{ }^{\circ} \mathrm{C}$, mean relative humidity was of $51 \%$ and total precipitation of $16 \mathrm{~mm}$. The city of Teresina is located within the tropical area and are exposed to high solar radiation intensities, a parameter responsible for the initiation of abiotic degradation in polymer materials and in the vegetal raw material due to its potential to break chemical bonds such as $\mathrm{CC}, \mathrm{CH}, \mathrm{CO}$, $\mathrm{OH}$, among others present in these materials ${ }^{[7,25]}$. One way to measure the intensity of ultraviolet radiation is by Ultraviolet Index (UVI), an integer that is presented in categories of intensities: if less than 2 intensity is low, between 3 and 5 is moderate, between 6 and 7 is high, between 8 and 10 is very high and greater than 11 is extreme (CPTEC-INPE, 2017).

Our data indicate that the samples suffered an intense incidence of UV radiation, as $76 \%$ of the time UVI was above 11 (Table 3). Also, UVI showed the highest value in October (weeks 5 to 8 ) and started to decrease slowly in November (week 9). This reduction is attributed to season transition as it corresponds to the end of spring to early summer which, in the region, is characterized as the rainy season.

Moisture, present in the environment, may also be responsible for physical or chemical degradation, as it can accelerate oxidation reactions and facilitate light penetration in the composites ${ }^{[10,26,27]}$. Water can reach the surface of samples exposed to weathering in several ways: as precipitation, relative humidity or water formed on the surface of the material as dew or condensation ${ }^{[25]}$. The results of precipitation levels showed rainfall in September and October with only $0.6 \mathrm{~mm}$ and a concentrated total of $15.4 \mathrm{~mm}$ in the month of November. This indicates that, until the first removal on 20/10/2017, there was minimal action of water by precipitation.

The relative air humidity varies considerably during the year. The first semester is characterized by higher humidity and the second semester is the driest. The variation of the relative humidity of the air during the period chosen for exposure to abiotic degradation (dry period) was quite low, with an average value of $51 \%$ in the 90 days of the test.

\subsection{Colorimetry}

The changes in color were determined by the Instrutherm ACR-1023 color meter equipment using the scales RGB (red, green and blue color components). The measurements were done directly on the surface of the samples.

\subsection{Optical Microscopy - OM}

The surface of the samples, prior and after abiotic degradation, were analyzed using an optical microscopy in a Leica Microsystems MD500 with ICC 50E capture camera operating in the reflection mode and at $40 \times$ magnification $(500 \mu \mathrm{m})$.

\subsection{Scanning Electron Microscopy - SEM}

SEM micrographs were obtained on an FEI Quanta FEG 250 equipment coupled with EDS Apollo XSDD, under $10 \mathrm{kV}$. The fracture surfaces of tensile tested eco-composite samples and of impact tested matrix were coated by a thin layer Gold with a Quorum Q150R ES metallizer and were analyzed with $300 \mathrm{X}$ magnification.

\subsection{Mechanical performance}

The mechanical performance of the eco-composites was ascertained by tensile testing conducted according to ASTM D 638 standards in an EMIC DL $30000 \mathrm{~N}$ universal testing machine operating with a $50 \mathrm{kN}$ load cell, $50 \mathrm{~mm} \cdot \mathrm{min}^{-1}$ the cross-head strain rate at room temperature. Mean and standard deviation values of elastic modulus, breaking and yield stress were calculated from 5 samples per composition.

Table 3. Summary of climatic conditions during the abiotic degradation test in the city of Teresina-PI.

\begin{tabular}{|c|c|c|c|c|c|}
\hline \multirow{2}{*}{ Week } & \multicolumn{2}{|c|}{ Average temperature $\left({ }^{\circ} \mathrm{C}\right)$} & \multirow{2}{*}{ UVI máx } & \multirow{2}{*}{ Precipitation (mm) } & \multirow{2}{*}{$\begin{array}{c}\text { Average relative } \\
\text { humidity }\end{array}$} \\
\hline & Máx & Mín & & & \\
\hline 1 & 37.80 & 18.10 & 11.50 & 0.00 & 48.50 \\
\hline 2 & 37.50 & 19.50 & 12.00 & 0.00 & 49.50 \\
\hline 3 & 37.90 & 20.10 & 12.40 & 0.00 & 51.50 \\
\hline 4 & 39.00 & 20.50 & 12.00 & 0.00 & 49.00 \\
\hline 5 & 38.40 & 22.30 & 12.30 & 0.00 & 49.50 \\
\hline 6 & 38.40 & 23.80 & 12.50 & 0.00 & 52.00 \\
\hline 7 & 39.10 & 22.40 & 12.40 & 0.60 & 49.50 \\
\hline 8 & 39.00 & 22.80 & 12.50 & 0.00 & 48.50 \\
\hline 9 & 38.30 & 22.00 & 12.10 & 0.00 & 48.50 \\
\hline 10 & 37.60 & 23.80 & 12.00 & 0.60 & 54.00 \\
\hline 11 & 37.80 & 22.80 & 11.80 & 1.40 & 51.00 \\
\hline 12 & 37.80 & 23.70 & 11.90 & 13.40 & 55.50 \\
\hline 13 & 37.40 & 22.50 & 11.60 & 0.00 & 50.00 \\
\hline
\end{tabular}

Source: INMET, 2017; Division of Satellites and Environmental Systems (DIDSA) of the Center for Weather Forecasting and Climate Studies (CPTEC) of the National Institute for Space Research (INPE), 2017. 


\subsection{Statistical analysis}

Variations in mechanical properties before and at the end of natural aging were analyzed using the R statistical computing platform (version 3.4.4, 2018) with scatter plots considering the results of non-aged and 90-day-aged samples. The properties that underwent major changes over the exposure periods were studied: maximum strength and deformation.

\section{Results and Discussions}

\subsection{Morphology}

Before OM and SEM analysis, the polymer and the eco-composites were visually inspected and showed that there a good dispersion of the cork particles in the matrix. The eco-composites displayed homogeneous tonality and good surface finish, the cork caused color change (Figure 1). Chemically modified samples with PEgMA showed a glossy appearance, better surface finish, and a darker shade, suggesting that the coupling agent altered filler wettability and promoted better interfacial bonding ${ }^{[4]}$.

\subsubsection{Colorimetry}

The measurements of color parameters and the effects of UV exposure were measured (Figure 2). Abiotic degradation caused bleaching of the eco-composites and this effect was more evident after 90 days of exposure. The discoloration is attributed to photodegradation of both cork and GPE, by different mechanisms, after exposure to ultraviolet light ${ }^{[5,7,28]}$. The main factor is the presence of chromophore groups in both polymer and lignin, which are responsible for the absorption of ultraviolet light (UV), thus intensifying sample photodegradation ${ }^{[8,22]}$.

Cork has an average lignin content of $27 \%{ }^{[14]}$ which, when degraded, produces water-soluble products, leading to the formation of functional chromophore groups, such as carboxylic acids, quinones, and hydroperoxide radicals ${ }^{[5,11]}$. Thus, the absorption of UV light initiates photochemical reactions on cork surfaces generating aromatic and other free radicals, which cause degradation of lignin and photooxidation of cellulose and hemicelluloses, effectively causing discoloration ${ }^{[5,29]}$.

The polymer, containing chromophore groups such as catalytic residues, hydroperoxide and carbonyl groups introduced during its manufacture, processing, and storage, absorb UV energy and initiate photochemical reactions that cause degradation and lead to cracking ${ }^{[30]}$. Oxygen diffusion into polyethylene controls its photodegradation, causing stresses that, combined with chain scission, can initiate and propagate cracks on the surface, leading to bleaching and loss of mechanical properties ${ }^{[31]}$.

In eco-composites without compatibilizers, the cork content alone did not significantly interfere in the results, since at the end of the test the parameters were very close. The color changes of chemically modified test samples were less intense than those observed with test samples without

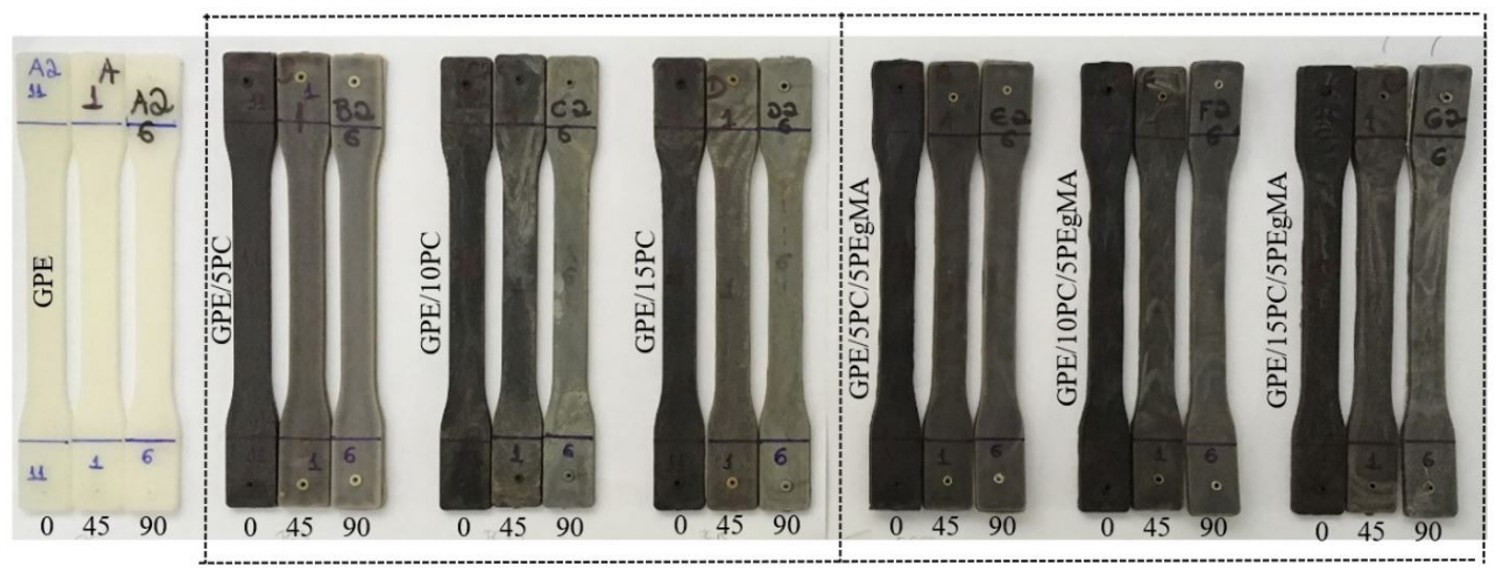

Figure 1. Test samples of the matrix and eco-composites before (0 days) and after natural aging (45 and 90 days).

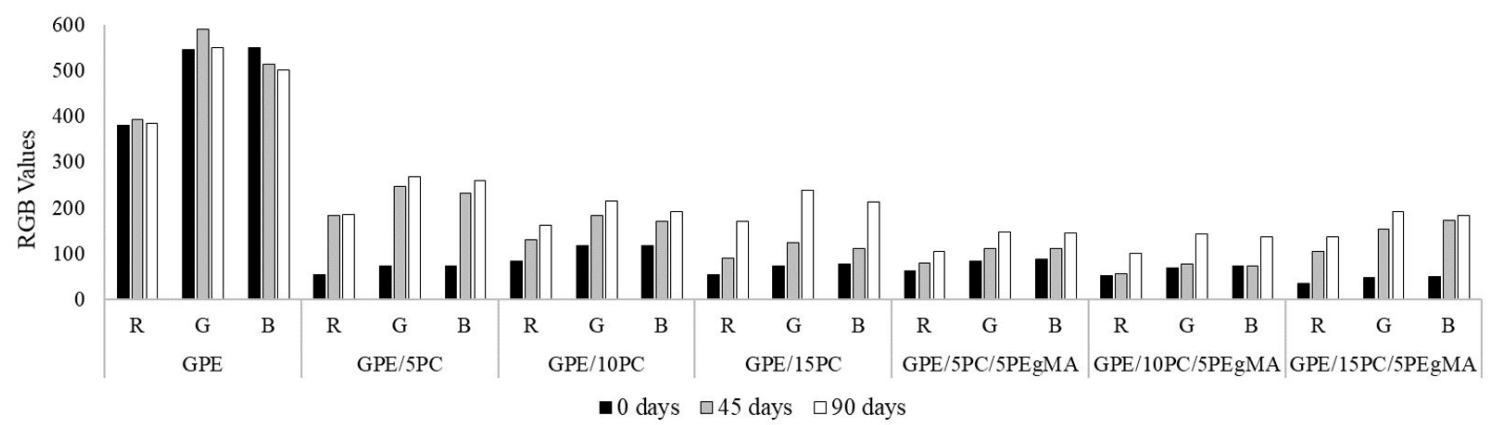

Figure 2. RGB values of the matrix and eco-composites before ( 0 days) and after exposure (45 and 90 days). 
PEgMA. According to Ndiaye et al. ${ }^{[32]}$ on their study on the durability of wood composites based on HDPE/PP and coupling agent, compatibilizer addition led to improved dispersion of the vegetal filler in the matrix and to reduced oxidation rate of the composites.

\subsubsection{Optical Microscopy - OM}

Optical micrographs of the composites illustrate the aspects observed during a visual inspection (Figure 3). Analysis of the non-aged sample surfaces confirms homogeneous distribution of the particles of cork powder, homogeneous tonality, bright appearance and good surface finish free of bubbles.

After exposure to UV radiation, although no loose cork particles were identified on the surface of the composite, cracks appeared on the surface of all samples investigated, thus confirming polymer degradation. The appearance of cracks upon weathering of vegetable fiber reinforced polymer composites is a common phenomenon attributed to the cleavage of the polymer chain, which allows the polymer to rapidly crystallize and leading to the formation of cracks in the composite surface ${ }^{[11,33]}$. The number of cracks appears to increase with the incorporation of cork, confirming that the presence of the filler weakens the material's resistance to natural weather conditions ${ }^{[11]}$. Spontaneous cracking of polymer may also occur due to secondary crystallization, also known as chemical crystallization ${ }^{[34]}$.

\subsubsection{Scanning Electron Microscopy - SEM}

To analyze the morphological changes before and after exposure to abiotic degradation of the systems, SEM images of the fracture surface of samples were taken (Figure 4).

It is important to note that, even before natural weathering, filler incorporation into the polymer matrix reduced the ability of the matrix to deform rendering the composite less ductile (more brittle) than the pure matrix. The increase in cork concentration was also responsible for the decrease of this characteristic, as can be seen when comparing the fracture surface of the composite GPE/5PC (Figure 4b) and GPE/15PC (Figure 4d) and the composite GPE/5PC/5PEgMA (Figure 4e) and GPE/15PC/5PEgMA (Figure 4g). Similar results were reported by Fernandes et al. ${ }^{[1]}$ on 1:1 polyethylene/cork composites. According to these authors, the system displayed brittle fracture, a result attributed to the high volume of cork powder content. In the present work, a comparison of samples of the same cork content with and without coupling agent (Fig. 4be, cf, dg) indicates that the incorporation of PEgMA increased the ability of the composite to deform, confirming that the addition of a polar compatibilizer is an effective strategy to improve interfacial adhesion ${ }^{[4,13,16]}$.
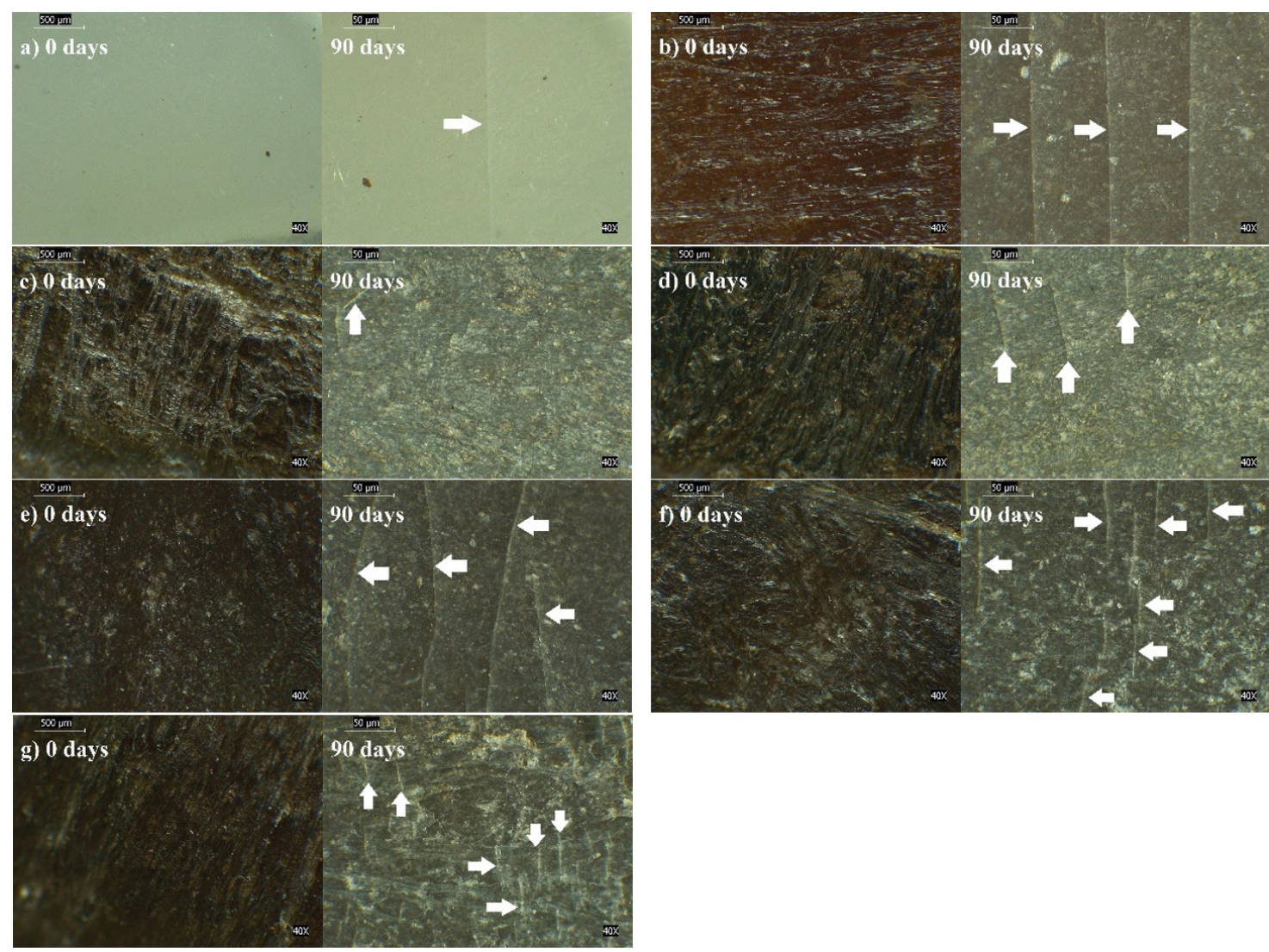

Figure 3. Images by OM on the surface of the GPE sample and its eco-composites before ( 0 days) and after the end of exposure to abiotic degradation (90 days), with 40X magnifications: (a) GPE; (b) GPE/5PC; (c) GPE/10PC; (d) GPE/15PC; (e) GPE/5PC/5PEgMA; (f) GPE/10PC/5PEgMA; e (g) GPE/15PC/5PEgMA. 
Vasconcelos, G. C. M. S., Carvalho, L. H., Barbosa, R., Idalino, R. C. L. \& Alves, T. S.
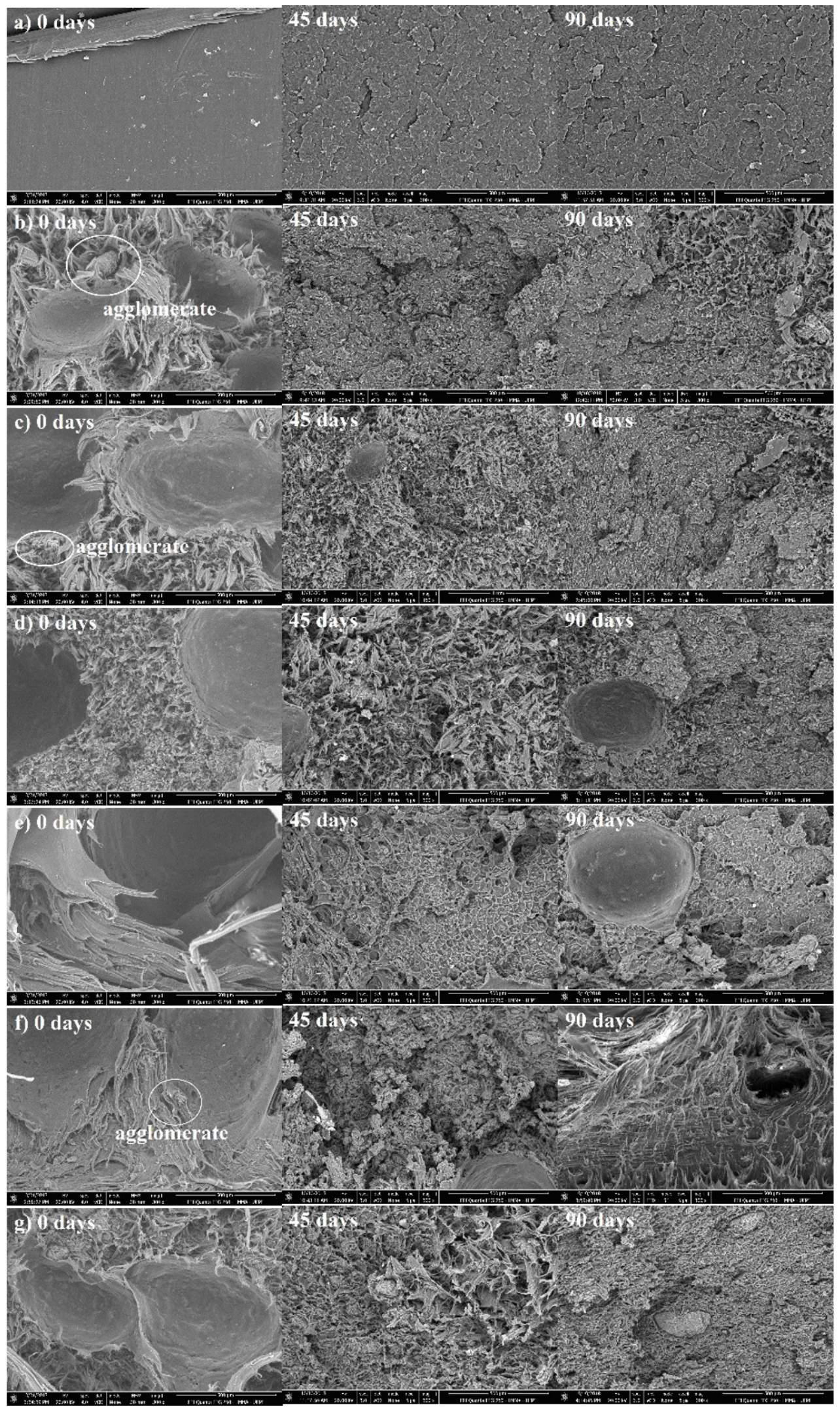

Figure 4. SEM micrographs of the GPE and their eco-composites on the fracture surface before (0 days) and after exposure to abiotic degradation (45 days and 90 days), with 300X magnifications: (a) GPE; (b) GPE/5PC; (c) GPE/10PC; (d) GPE/15PC; (e) GPE/5PC/5PEgMA; (f) GPE/10PC/5PEgMA; e (g) GPE/15PC/5PEgMA. 
In general, after natural weathering, there were large changes in the morphology of the GPE samples (Figure 4a), allowing significant change to be observed as soon as after 45 days of exposure. The fracture surfaces of weathered samples were brittle, rough with the appearance of flaky structures, suggesting the existence of internal fractures. According to Fabiyi et al. ${ }^{[8]}$, the cracks can be caused by polymer chain scission, which results in highly crystallized polymer zones that crack and/or differentially contract (resulting from wetting and drying cycles) between the surface and interior sections. Similar findings were observed in studies by Yang et al. ${ }^{[24]}$ when analyzing HDPE composites reinforced with different inorganic fillers. In this work, particles and whitish regions were also observed. According to Yang et al. ${ }^{[23]}$, these structures are attributed to matrix spherulites, formed in the amorphous region of the polymer and exposed on the fracture surface and confirm that photooxidative degradation of the polymer matrix starts preferentially in the amorphous region of the material, since the crystalline region has a higher density, reducing the diffusion of oxygen.

In the microscopies of the eco-composites, before abiotic degradation, it was possible to see the elongation of the GPE between the cork cell walls (Figure 4b), suggesting good interaction between the phases ${ }^{[13]}$. However, despite the good affinity, some filler clusters were identified (Figure 4b, c, f, g). Bledzki, Reihmane $\&$ Gassan $^{[35]}$ point out that one of the main problems in the processing of wood/thermoplastic composites is the tendency of the natural filler, when untreated, to form large agglomerates due to the high intermolecular bond between the fibers, a feature that should be considered when choosing processing conditions. Since cork is a raw material similar to wood, this justifies the formation of the observed agglomerates. After 45 days of weathering, the surface of the composites became rougher, as shown by a flaky appearance identified in the micrographs of the pure polymer and more apparent in the samples without compatibilizer. The samples taken at the end of the exposure time (90 days) did not show significant changes when compared to those with 45 days of exposure.

\subsection{Tensile Testing}

The mechanical properties of the eco-composites are shown in Table 4 and Figure 5.
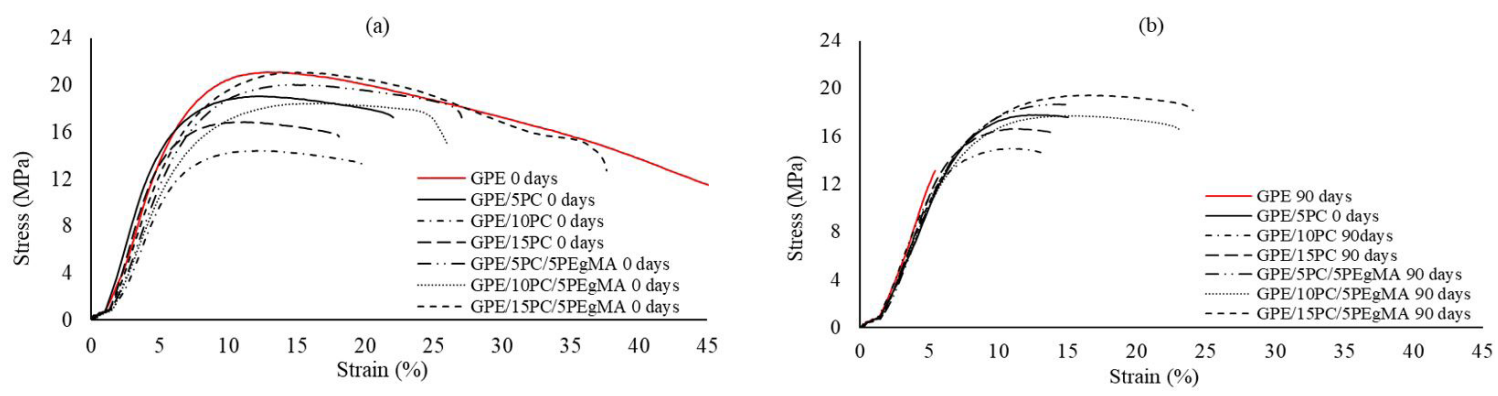

Figure 5. Stress-strain graphs of GHDPE and the eco-composites (a) before and (b) after weathering.

Table 4. Elastic of Modulus, Breaking stress and Yield stress of the GPE and composites before and after weathering.

\begin{tabular}{|c|c|c|c|c|}
\hline \multirow{2}{*}{ Sample } & \multirow{2}{*}{$\begin{array}{c}\text { Exposure time } \\
\text { (days) }\end{array}$} & \multicolumn{3}{|c|}{ Period: 9/4/2017 e 12/3/2017 } \\
\hline & & Elastic of Modulus (MPa) & Breaking stress (MPa) & Yield stress (MPa) \\
\hline \multirow[t]{3}{*}{ GPE } & 0 & $379.00 \pm 12.32$ & $4.19 \pm 1.38$ & $9.89 \pm 0.65$ \\
\hline & 45 & $362.77 \pm 25.60$ & $17.93 \pm 1.00$ & $12.73 \pm 0.96$ \\
\hline & 90 & $359.17 \pm 10.78$ & $12.63 \pm 1.00$ & $9.50 \pm 0.96$ \\
\hline \multirow[t]{3}{*}{ GPE/5PC } & 0 & $407.57 \pm 21.07$ & $16.52 \pm 0.88$ & $9.68 \pm 0.17$ \\
\hline & 45 & $305.98 \pm 1.13$ & $16.80 \pm 0.65$ & $8.25 \pm 1.29$ \\
\hline & 90 & $321.80 \pm 6.88$ & $17.30 \pm 0.17$ & $10.13 \pm 0.80$ \\
\hline \multirow[t]{3}{*}{ GPE/10PC } & 0 & $336.90 \pm 29.27$ & $11.27 \pm 1.07$ & $8.02 \pm 0.56$ \\
\hline & 45 & $248.23 \pm 5.09$ & $12.30 \pm 1.44$ & $8.18 \pm 1.17$ \\
\hline & 90 & $297.78 \pm 5.18$ & $14.34 \pm 0.82$ & $7.16 \pm 2.34$ \\
\hline \multirow[t]{3}{*}{$\mathrm{GPE} / 15 \mathrm{PC}$} & 0 & $371.08 \pm 28.84$ & $13.58 \pm 1.44$ & $7.93 \pm 0.73$ \\
\hline & 45 & $243.70 \pm 2.68$ & $14.07 \pm 0.86$ & $7.97 \pm 1.68$ \\
\hline & 90 & $309.72 \pm 9.23$ & $15.08 \pm 0.82$ & $9.50 \pm 0.99$ \\
\hline \multirow[t]{3}{*}{ GPE/5PC/PEgMA } & 0 & $329.90 \pm 8.47$ & $11.82 \pm 0.90$ & $9.22 \pm 0.68$ \\
\hline & 45 & $242.96 \pm 8.06$ & $16.16 \pm 1.23$ & $10.02 \pm 1.10$ \\
\hline & 90 & $297.57 \pm 4.89$ & $17.63 \pm 1.16$ & $9.40 \pm 0.61$ \\
\hline \multirow[t]{3}{*}{ GPE/10PC/PEgMA } & 0 & $299.80 \pm 22.54$ & $13.03 \pm 1.72$ & $9.09 \pm 0.62$ \\
\hline & 45 & $279.20 \pm 17.87$ & $16.10 \pm 0.90$ & $9.50 \pm 1.47$ \\
\hline & 90 & $293.73 \pm 5.96$ & $14.70 \pm 0.78$ & $8.43 \pm 0.92$ \\
\hline \multirow[t]{3}{*}{ GPE/15PC/PEgMA } & 0 & $351.00 \pm 15.43$ & $10.00 \pm 1.22$ & $9.70 \pm 0.47$ \\
\hline & 45 & $280.57 \pm 1.40$ & $12.00 \pm 1.49$ & $10.40 \pm 0.60$ \\
\hline & 90 & $315.93 \pm 24.2$ & $17.25 \pm 2.81$ & $8.98 \pm 0.74$ \\
\hline
\end{tabular}


The data indicates that, prior to weathering, the elastic modulus of the composites did not significantly change with cork incorporation, as a slight increase of $7.50 \%$ for GPE/5PC and a decrease of $11.1 \%$ and $2.1 \%$ for the GPE/10PC and $\mathrm{GPE} / 15 \mathrm{PC}$ samples, respectively, relative to the pure matrix were observed (Table 4). Similar behavior was reported by Fernandes et al. ${ }^{[17]}$ and Brites et al. ${ }^{[36]}$, which identified an improvement in the stiffness of the material with increasing load when analyzing cork/polyolefin composites. In this work, the use of the PEgMA did not significantly change elastic modulus values of the composites when compared to the untreated samples with the same cork content, except for GPE/5PC/5PEgMA, which presented a reduced value compared to the GPE/5PC. Fernandes et al. ${ }^{[17]}$ found similar results when producing polypropylene/cork powder (15\%) composites. According to those autors, the introduction of a coupling agent functionalized with maleic anhydride - PP-g-MA ( $2 \%$ and 4\%) - reduced composite stiffness compared to the untreated composite. The other samples treated with the coupling agent, GHDPE/10CP/5PE-g-MA and GHDPE/15CP/5PE-g-MA, showed no significant changes in this property.

After abiotic degradation, Young's modulus of the GPE did not change significantly when compared to the non-exposed polymer, which is attributed to the fact that GPE has a higher percentage of crystalline phase ${ }^{[37]}$ impermeable to $\mathrm{O}_{2}$ and $\mathrm{H}_{2} \mathrm{O}$, thus limiting and slowing degradation reactions as these predominantly occur in the amorphous phases ${ }^{[27,38,39]}$. Regarding the eco-composites, it was clearly observed that the modulus of all compositions, with and without PEgMA, were reduced after 45 days of exposure. When compared to non-exposed samples of the same composition, the decreases in modulus observed were approximately 20-34\% for GPE/5PC, GPE/10PC, GPE/15PC, GPE/5PC/5PEgMA, and GPE/15PC/5PEgMA. The composition GPE/10PC/5PEgMA had less loss of stiffness ( $7 \%$ ) when compared to non-aged samples. Some studies suggest that part of this loss in modulus can be attributed to the appearance of cracks in the surface due to photodegradation, which promotes a decrease in the interfacial bond between the cork and the polymer matrix and, consequently, the embrittlement of the material ${ }^{[11,31]}$. In this study, the appearance of surface cracks is confirmed by optical microscopy images (Figure 3). The tests performed at the end of 90 days showed a tendency to recover the modulus, which could be associated with a chemical crystallization process, in which radicals formed by molecular chain cleavages in the amorphous phase on the sample surface during degradation are recombined ${ }^{[31]}$. It is an interesting feature for the application of these materials in provisional constructions that have a useful life within the studied period.

Breaking stress data (Table 4) clearly demonstrated cork addition effects on this property. Before natural aging, the highest value for this property was obtained with GPE/5PC eco-composite which was at least $122 \%$ higher and up to $165 \%$ higher than all other systems developed. With high polymer content, cork can be fully encapsulated by the matrix, which helps to disperse the reinforcing particles, improves the stress distribution and increases breaking stress ${ }^{[9]}$. Except for GPE/5PC/5PEgMA which showed a $28 \%$ decrease in breaking stress compared to the GPE/5PC sample, all breaking stress values of coupling agent-treated eco-composites were similar to those containing the untreated filler.

After the first 45 days of natural weathering, the GPE samples showed an increase in this property followed by a reduction at the end of 90 days. Results showed a fragile behavior of the degraded sample, which requires a lower breaking force.

SEM images (Figure 4a) show a rough, flaky degraded surface of weathered samples, suggesting the existence of internal fractures. The breaking stress values of non-compatibilized eco-composites did not change significantly with natural aging when compared with compatibilized samples of equivalent composition. Actually, significant growth in this property was obtained for the samples formulated with PEgMA aged for 45 days, which may be associated with secondary crystallization processes, induced by short macromolecular chains resulting from an amorphous chain cleavage of the polymer during UV weathering ${ }^{[40]}$.

The yield stress was also used to monitor changes in the mechanical behavior of the eco-composites as a function of filler content, coupling agent addition, and weathering. Before exposure, when compared to GPE, results indicated similar yield stress values for GPE/5PC and decreases for GPE/10PC and GPE/15PC, 19\% and 20\% respectively, which was interpreted as cork particles having low strain (smaller than the matrix) and acting as stress concentrators, accelerating the propagation of cracks $^{[41-43]}$. SEM images confirm this change since it is noticeable that the $5 \%$ cork composites had a higher yield than the composites with 15\% (Figure 4b, d, Figure 4e, g). The yield stress of the systems increases upon PEgMA addition and with higher cork concentrations, which is attributed to better interfacial adhesion, filler distribution and stress transfer to the particles which promote the efficient distribution of the applied stress, thereby maintaining similar flow stress values to the neat polymer. No significant changes in this property were observed after weathering. Our data indicate that the yield stress was not affected by the weather in the proposed period of 90 days, thus presenting values of yield stress similar to those of the eco-composites, with and without compatibilizer.

The tensile strength and the maximum strain for the GPE and eco-composites were analyzed and showed the deformation profile characteristic of ductile material for the pure polymer whereas the composites were typical of lower ductility materials (Figure 5).

The curves of the non-aged samples showed a deformation profile characteristic of ductile material for the pure polymer whereas those of the composites are typical of lower ductility materials. The results also indicate that the tensile strength and the maximum deformation of the composites were reduced with the incorporation of cork, especially for the non-compatibilizing and high-grade composites GPE/10PC and GPE/15CP. This reduction can be attributed to the incompatibility between cork particles and the polymer matrix. The lack of adhesion between the phases limits the load transfer between them, resulting in a decrease of the tensile strength since the stress cannot be transferred by the matrix ${ }^{[17,36]}$. Another factor that may have influenced this behavior is that cork has lower mechanical properties 
a) maximum strenght $(\mathrm{N})$

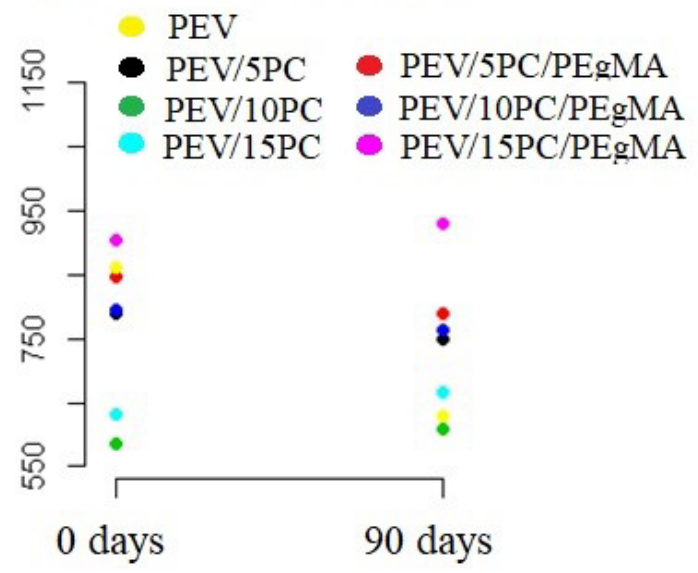

b) Strain (mm)

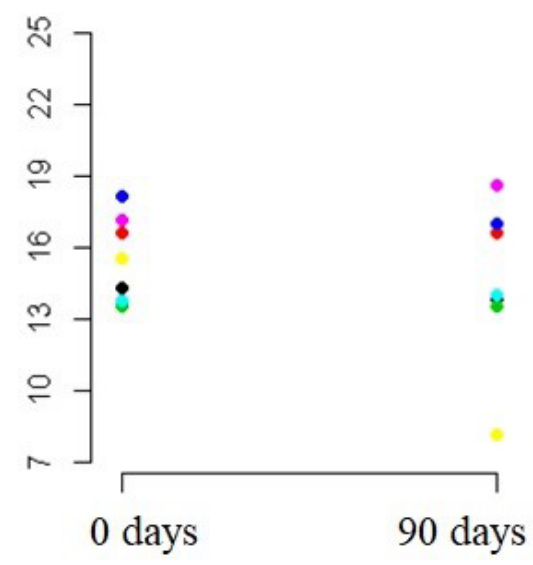

Figure 6. Average dispersion of (a) Maximum Force and (b) Deformation of samples before and after natural aging.

under tensile load when compared to the polyethylene matrix, contributing to the decrease in tensile strength. Some authors suggest incorporating coupling agents, for example, functionalized polymers containing maleic anhydride groups in the composition to improve interfacial adhesion ${ }^{[4,16]}$. In this study, the addition of PEgMA allowed the recovery of tensile strength and maximum deformation proving the efficiency of the compatibilizing agent in improving the adhesion between phases.

In the curves plotted after aging it was possible to notice a typical behavior of materials with low ductility for the matrix, with reduced tensile and deformation resistance, and a less intense variation in the eco-composite curves. Badji et al. [11] found similar mechanical performance to natural and artificial aging of polypropylene and wood flour compound, who attributed the observed behavior to the stabilizing role of lignin contained in wood flour. The curves also showed that the presence of compatibilizer was fundamental in maintaining tensile strength, but that due to the load size, a reduction in deformation could not be avoided. Natural weatherin led to an intense reduction in plastic deformation of the matrix while that property was not affected for the composites, despite the observed decrease in their strain at break. The compatibilized composites GPE/15CP/PEgMA and GPE/10CP/PEgMA higher tensile strength and strain at break than the other composites after 90 days aging.

The spread on mechanical properties results were satisfactory, considering that they are below $10 \%$ and in accordance with the literature.

\subsection{Statistical analysis}

The statistical analysis allowed us to investigate the mechanical properties found for non-aged and aged samples and to suggest which composition was more mechanically stable before and after the abiotic degradation. Figure 6 shows the variations of the maximum strength and strain at break (deformation capacity) throughout abiotic degradation.

These results confirm what was observed in Figure 5. Prior to weathering, the incorporation of cork in higher contents (10 and $15 \%)$ was responsible for weakening the material and reducing its strain at break when submitted to a tensile test. The GPE/5PC composite had a similar deformation to GPE and the PEgMA compatibilizer improved the compatibility between the phases increasing their deformation capacity and consequently their maximum strength values. After weathering, GPE showed loss of strength and the compatible composites performed well even after exposure. The highlight is the GPE/15PC/5PEgMA, which presented the highest value of maximum force and deformation capacity, and similar values before and after the abiotic degradation period. The composites without PEgMA had lower values of these properties, however, they were constant under the studied aging conditions. In general, it can be stated that the 90-day exposure period did not significantly impact on the loss of mechanical properties of composites when compared to GPE.

\section{Conclusions}

Aging caused by natural weathering promoted some aesthetic changes on the eco-composites such as surface bleaching and cracking. OM showed that the filler particles were coated by the polymer matrix as no loose cork particles were observed on the surface of the composites. SEM images of the fractured surfaces detected a rougher, flakier appearance, after weathering of all samples investigated.

Althougj natural aging led to a reduction in tensile strength and elastic deformation of the eco-composites, the incorporation of PEgMA was fundamental for the maintenance of mechanical performance. In general, the mechanical property results obtained were satisfactory for external applications of the GPE/15PC/5PEgMA eco-composite in the proposed weathering range, which indicates its possible use in temporary constructions.

\section{References}

1. Geyer, R., Jambeck, J. R., \& Law, K. L. (2017). Production, use, and fate of all plastics ever made. Science Advances, 3(7), e170078. http://dx.doi.org/10.1126/sciadv.1700782. PMid:28776036. 
2. Halliwell, S. M. (2002). Polymers in building and construction. United Kingdom: Rapra Technology Limited.

3. Bajwa, D. S., Bajwa, S. G., \& Holt, G. A. (2015). Impact of biofibers and coupling agents on the weathering characteristics of composites. Polymer Degradation and Stability Journal, 120, 212-219. http://dx.doi.org/10.1016/j.polymdegradstab.2015.06.015.

4. Fernandes, E. M., Mano, J. F., \& Reis, R. L. (2013). Hybrid cork-polymer composites containing sisal fiber: Morphology, the effect of the fiber treatment on the mechanical properties and tensile failure prediction. Composite Structures, 105, 153162. http://dx.doi.org/10.1016/j.compstruct.2013.05.012.

5. Feist, W. C., \& Hon, D. N.-S. (1984). Chemistry of Weathering and Protection. In R. Rowell. The chemistry of solid wood (pp. 401-451). Washington: American Chemical Society. http:// dx.doi.org/10.1021/ba-1984-0207.ch011.

6. Lundin, T., Falk, R. H., \& Felton, C. (2001). Accelerated weathering of natural fiber thermoplastic composites: effects of ultraviolet exposure on bending strength and stiffness. In Sixth International Conference on Woodfiber-Plastic Composites ( $\mathrm{p}$. 8793). Wisconsin: Forest Products Society.

7. Matuana, L. M., Jin, S., \& Stark, N. M. (2011). Ultraviolet weathering of HDPE/wood-flour composites coextruded with a clear HDPE cap layer. Polymer Degradation \& Stability, 96(1), 97-106. http://dx.doi.org/10.1016/j.polymdegradstab.2010.10.003.

8. Fabiyi, J. S., McDonald, A. G., Wolcott, M. P., \& Griffiths, P. R. (2008). Wood plastic composites weathering: visual appearance and chemical changes. Polymer Degradation and Stability Journal, 93(8), 1405-1414. http://dx.doi.org/10.1016/j. polymdegradstab.2008.05.024.

9. Ratanawilai, T., \& Taneerat, K. (2018). Alternative polymeric matrices for wood-plastic composites: effects on mechanical properties and resistance to natural weathering. Construction \& Building Materials, 172, 349-357. http://dx.doi.org/10.1016/j. conbuildmat.2018.03.266.

10. Stark, N. M., \& Matuana, L. M. (2006). Influence of photostabilizers on wood flour-HDPE composites exposed to xenon-arc radiation with and without water spray. Polymer Degradation \& Stability, 91(12), 3048-3056. http://dx.doi. org/10.1016/j.polymdegradstab.2006.08.003.

11. Badji, C., Soccalingame, L., Garay, H., Bergeret,A., \& Bénézet, J. C. (2017). Influence of weathering on visual and surface aspect of wood plastic composites: correlation approach with mechanical properties and microstructure. Polymer Degradation and Stability Journal, 137, 162-172. http://dx.doi.org/10.1016/j. polymdegradstab.2017.01.010.

12. Fernandes, E. M., Aroso, I. M., Mano, J. F., Covas, J. A., \& Reis, R. L. (2014). Functionalized cork-polymer composites $(\mathrm{CPC})$ by reactive extrusion using suberin and lignin from cork as coupling agents. Composites. Part B, Engineering, 67, 371-380. http://dx.doi.org/10.1016/j.compositesb.2014.07.028.

13. Fernandes, E. M., Correlo, V. M., Chagas, J. A. M., Mano, J. F., \& Reis, R. L. (2011). Properties of new cork-polymer composites: advantages and drawbacks as compared with commercially available fibreboard materials. Composite Structures, 93, 3120-3129. http://dx.doi.org/10.1016/j. compstruct.2011.06.020.

14. Gil, L. (2012). Cortiça. In M. C. Gonçalves, \& F. Margarido (Eds.), Ciência e engenharia de materiais de construção (pp. 663-715). Lisboa: IST Press.

15. Pereira, H., Emília Rosa, M., \& Fortes, M. A. (1987). The cellular structure of cork from Quercus Suber L. IAWA Journal, 8(3), 213-218. http://dx.doi.org/10.1163/22941932-90001048.

16. Fernandes, E. M., Correlo, V. M., Chagas, J. A. M., Mano, J. F., $\&$ Reis, R. L. (2010). Cork based composites using polyolefin's as matrix: morphology and mechanical performance. Composites
Science and Technology, 70(16), 2310-2318. http://dx.doi. org/10.1016/j.compscitech.2010.09.010.

17. Fernandes, E. M., Correlo, V. M., Mano, J. F., \& Reis, R. L. (2014). Polypropylene-based cork-polymer composites: processing parameters and properties. Composites. Part $B$, Engineering, 66, 210-223. http://dx.doi.org/10.1016/j. compositesb.2014.05.019.

18. Silva, S. P., Sabino, M. A., Fernandes, E. M., Correlo, V. M., Boesel, L. F., \& Reis, R. L. (2005). Cork: properties, capabilities, and applications. International Materials Reviews, 50(6), 345-365. http://dx.doi.org/10.1179/174328005X41168.

19. Boronat, T., Fombuena, V., Garcia-Sanoguera, D., SanchezNacher, L., \& Balart, R. (2015). Development of a biocomposite based on green polyethylene biopolymer and eggshell. Materials \& Design, 68, 177-185. http://dx.doi.org/10.1016/j. matdes.2014.12.027.

20. Bledzki, A. K., \& Gassan, J. (1996). Composites Reinforced with Cellulose Based Fibers. Progress in Polymer Science, 24(2), 221-274. http://dx.doi.org/10.1016/S0079-6700(98)00018-5.

21. Fernandes, E. M., Correlo, V. M., Mano, J. F., \& Reis, R. L. (2013). Novel cork-polymer composites reinforced with short natural coconut fibers: effect of fiber loading and coupling agent addition. Composites Science and Technology, 78, 56-62. http://dx.doi.org/10.1016/j.compscitech.2013.01.021.

22. Andrady, A. L., Hamid, S. H., Hu, X., \& Torikai, A. (1998). Effects of increased solar ultraviolet radiation on materials. Journal of Photochemistry and Photobiology. B, Biology, 46(13), 96-103. http://dx.doi.org/10.1016/S1011-1344(98)00188-2. PMid:9894353.

23. Valadez, A., \& Veleva, L. (2004). Mineral filler influence on the photo-oxidation mechanism degradation of high-density polyethylene. Part II: natural exposure test. Polymer Degradation \& Stability, 83(1), 139-148. http://dx.doi.org/10.1016/S01413910(03)00246-5.

24. Yang, R., Yu, J., Liu, Y., \& Wang, K. (2005). Effects of inorganic fillers on the natural photo-oxidation of high-density polyethylene. Polymer Degradation \& Stability, 88(2), 333-340. http://dx.doi.org/10.1016/j.polymdegradstab.2004.11.011.

25. Jacques, L. F. E. (2000). Accelerated and outdoor/natural exposure testing of coatings. Progress in Polymer Science, 25(9), 1337-1362. http://dx.doi.org/10.1016/S0079-6700(00)00030-7.

26. Stark, N. (2006). Effect of weathering cycle and manufacturing method on performance of wood flour and high-density polyethylene composites. Journal of Applied Polymer Science, 100(4), 3131-3140. http://dx.doi.org/10.1002/app.23035.

27. Stark, N. M., Matuana, L. M., \& Clemons, C. M. (2004). Effect of processing method on surface and weathering characteristics of wood-flour/HDPE composites. Journal of Applied Polymer Science, 93(3), 1021-1030. http://dx.doi.org/10.1002/app.20529.

28. Pandey, P., Bajwa, S. G., Bajwa, D. S. \& Englund, K. (2017). Performance of UV weathered HDPE composites containing hull fiber from DDGS and corn grain. Industrial Crops \& Products journal, 107, 409-419. http://dx.doi.org/10.1016/j. indcrop.2017.06.050.

29. Pandey, K. (2005). Study of the effect of photo-irradiation on the surface chemistry of wood. Polymer Degradation \& Stability, 90(1), 9-20. http://dx.doi.org/10.1016/j. polymdegradstab.2005.02.009.

30. Grum, J. (2008). Book Review: Plastics additives handbook, 5th Edition by H. Zweifel. International Journal of Microstructure and Materials Properties, 3(2-3), 451. http://dx.doi.org/10.1504/ ijmmp.2008.018747.

31. Yakimets, I., Lai, D., \& Guigon, M. (2004). Effect of photooxidation cracks on behavior of thick polypropylene samples. Polymer Degradation \& Stability, 86(1), 59-67. http://dx.doi. org/10.1016/j.polymdegradstab.2004.01.013. 
32. Ndiaye, D., Fanton, E., Morlat-Therias, S., Vidal, L., Tidjani, A., \& Gardette, J.-L. (2008). The durability of wood polymer composites: Part 1. Influence of wood on the photochemical properties. Composites Science and Technology, 68(13), 27792784. http://dx.doi.org/10.1016/j.compscitech.2008.06.014.

33. Rabello, M. S., \& White, J. R. (1997). Crystallization and melting behavior of photodegraded polypropylene-I. Chemicrystallization. Polymer, 38(26), 6379-6387. http://dx.doi. org/10.1016/S0032-3861(97)00213-9.

34. Craig, I. H., \& White, J. R. (2005). Crystallization and chemicrystallization of recycled photodegraded polyethylenes. Polymer Engineering and Science, 45(4), 588-595. http:// dx.doi.org/10.1002/pen.20314.

35. Bledzki, A. K., Reihmane, S., \& Gassan, J. (1998). Thermoplastics Reinforced with Wood Fillers: A Literature Review. PolymerPlastics Technology and Engineering, 37(4), 451-468. http:// dx.doi.org/10.1080/03602559808001373.

36. Brites, F., Malça, C., Gaspar, F., Horta, J. F., Franco, M. C., Biscaia, S., \& Mateus, A. (2017). Cork plastic composite optimization for 3D Printing Applications. Procedia Manufacturing, 12, 156-165. http://dx.doi.org/10.1016/j.promfg.2017.08.020.

37. Visakh, P., \& Martinez Morlanes, M. (2015). PolyethyleneBased Blends, Composites, and Nanocomposites: Stateof-the-Art, New Challenges, and Opportunities. In P. M. Visakh, M. J. Martínez Morlanes, Polyethylene Based Blends, Composites, and Nanocomposites (pp. 1-19). http://dx.doi. org/10.1002/9781118831328.ch1

38. Jakubowicz, I. (2003). Evaluation of degradability of biodegradable polyethylene (PE). Polymer Degradation \& Stability, 80(1), 39-43. http://dx.doi.org/10.1016/S0141-3910(02)00380-4.
39. Lucas, N., Bienaime, C., Belloy, C., Queneudec, M., Silvestre, F., \& Nava-Saucedo, J. E. (2008). Polymer biodegradation: Mechanisms and estimation techniques - A review. Chemosphere, 73(4), 429-442. http://dx.doi.org/10.1016/j. chemosphere.2008.06.064. PMid:18723204.

40. Fayolle, B., Richaud, E., Verdu, J., \& Farcas, F. (2008). Embrittlement of polypropylene fiber during thermal oxidation. Journal of Materials Science, 43(3), 1026-1032. http://dx.doi. org/10.1007/s10853-007-2242-1.

41. Essabir, H., Hilali, E., Elgharad, A., El Minor, H., Imad, A., Elamraoui, A., \& Al Gaoudi, O. (2013). Mechanical and thermal properties of bio-composites based on polypropylene reinforced with Nut-shells of Argan particles. Materials \& Design, 49, 442-448. http://dx.doi.org/10.1016/j.matdes.2013.01.025.

42. Essabir, H., Nekhlaoui, S., Malha, M., Bensalah, M. O., Arrakhiz, F. Z., Qaiss, A., \& Bouhfid, R. (2013). Bio-composites based on polypropylene reinforced with Almond Shell particles: mechanical and thermal properties. Materials \& Design, 51, 225-230. http://dx.doi.org/10.1016/j. matdes.2013.04.031.

43. Essabir, H., Bensalah, M. O., Rodrigue, D., Bouhfid, R., \& Qais, A. E. K. (2016). Biocomposites based on Argan nutshell and a polymer matrix: effect of filler content and coupling agent. Carbohydrate Polymers, 143, 70-83. http://dx.doi. org/10.1016/j.carbpol.2016.02.002. PMid:27083345.

Received: Aug. 19, 2019

Revised: May 29, 2020

Accepted: June 16, 2020 